\title{
Efeitos de adições minerais para mitigação de reações álcali- agregado no concreto: estado da arte
}

O concreto é um material de construção civil que tem seu uso disseminado no mundo todo. Alguns fatores, como a escolha de materiais e manuseio inadequados, assim como a exposição a ambientes agressivos, podem gerar patologias nesse material. A deterioração, por exemplo, pode ocorrer na parte interna do material, como é o caso da reação álcali-agregado (RAA), onde os álcalis que existem na pasta de cimento interagem com os minerais reativos do agregado. Esse tipo de reação pode resultar em um gel expansivo, onde ao se dispor nos vazios do concreto e na superfície do agregado em contato com a pasta de cimento, pode ocasionar fissuras generalizadas, e assim comprometer a qualidade da estrutura. As RAA podem ser de três tipos: reação álcali-sílica; reação álcali-silicato; e reação álcali-carbonato. Cada tipo de reação depende da composição mineralógica reativa do agregado. Diante dos problemas gerados pelas RAA, diversos estudos têm procurado maneiras de minimizar estes efeitos. Um dos métodos mais utilizados para reduzir os impactos causados pelas RAA é a utilização de adições minerais. Desta forma, este trabalho objetivou fazer uma busca no estado da arte sobre os efeitos das principais adições minerais utilizadas para mitigar as RAA. Ficou evidenciado, a partir dos resultados vistos, que a adição de materiais pozolânicos em concretos e argamassas para mitigar as RAA pode ser bastante eficaz. Observou-se que as adições mais utilizadas são a cinza de casca de arroz, cinza volante, escória granulada de alto forno, escória de aciaria, sílica ativa e metacaulim. Alguns resultados possibilitaram concluir que estas adições ajudam a reduzir as expansões nas RAA, porém, se não tiver um teor ótimo, podem agir de forma contrária, facilitando as reações.

Palavras-chave: Patologia; Reação álcali-agregado; Adições Minerais.

\section{Effects of mineral additions for the mitigation of alkali-aggregate reactions in concrete: state of the art}

\begin{abstract}
Concrete is a building material that has its widespread use worldwide. Some factors, such as the choice of inappropriate materials and handling, as well as exposure to aggressive environments, can lead to pathologies in this material. Deterioration, for example, can occur in the inner part of the material, such as the alkali aggregate (RAA) reaction, where the alkalis in the cement paste interact with the reactive minerals in the aggregate. This type of reaction can result in an expansive gel, where it can cause generalized fissures and thus compromise the quality of the structure when it is placed in the voids of the concrete and the surface of the aggregate in contact with the cement paste. The RAA can be of three types: alkali-silica reaction; alkali silicate reaction; and alkali-carbonate reaction. Each type of reaction depends on the reactive mineralogical composition of the aggregate. Faced with the problems generated by the RAA, several studies have looked for ways to minimize these effects. One of the methods most used to reduce the impacts caused by RAA is the use of mineral additions. In this way, this work aimed to search the state of the art on the effects of the main mineral additions used to mitigate the RAA. It was evidenced from the results that the addition of pozzolanic materials in concretes and mortars to mitigate RAA can be quite effective. It was observed that the most used additions are rice husk ash, fly ash, granulated blast furnace slag, steel slag, active silica and metakaolin. Some results have made it possible to conclude that these additions help to reduce the expansions in the AAR, but if they do not have an optimal content, they can act in the opposite way, facilitating the reactions.
\end{abstract}

Keywords: Pathology; Alkali-aggregate reaction; Mineral Additions.

Topic: Engenharia Civil

Reviewed anonymously in the process of blind peer.

Yuri Sotero Bomfim Fraga

Universidade de Brasília, Brasil

http://lattes.cnpq.br/5055016786232011

yurisotero.engcivil@gmail.com

Carla Mabel Medeiros de Albuquerque e Silva

Universidade de Brasília, Brasil

http://lattes.cnpq.br/1243248867034312

carlamabeleng@gmail.com
Received: 12/07/2017

Approved: 11/10/2017
Referencing this:

FRAGA, Y. S. B.; SILVA, C. M. M. A.. Efeitos de adições minerais para mitigação de reações álcali-agregado no concreto: estado da arte. Engineering Sciences, v.5, n.1, p.1-13, 2017. DOI: http://doi.org/10.6008/SPC2318-3055.2017.001.0001 


\section{INTRODUÇÃO}

O concreto é um dos materiais mais antigos e que tem o uso mais disseminado na construção civil. Fazem parte da sua composição aglomerante hidráulico - cimento Portland, agregado miúdo, agregado graúdo, água, podendo ainda conter aditivos químicos e adições. Algumas propriedades fazem com que esse material seja o mais aplicado na engenharia, desde a facilidade de executar elementos diversos, em variedade de dimensões e geometria, ao baixo custo e maior disponibilidade.

Alguns fatores como a escolha de materiais e manuseio inadequados, assim como a exposição à ambientes agressivos podem gerar uma série de patologias no concreto. De acordo com Lapa (2008), com o advento das tecnologias e metodologias de diagnóstico de patologias em estruturas, tem-se observado diversos problemas ligados ao mal emprego e execução do concreto.

Segundo Fusco (1976), quando o ambiente externo interage com o concreto, pode haver a interação combinada de agentes biológicos, químicos e físicos, os quais minoram a durabilidade do concreto. Poggiali (2009) diz que as patologias do concreto com causas químicas se dão pela interação dos agentes externos com os constituintes da pasta de cimento.

A reação álcali-agregado (RAA) é considerada uma reação química que ocorre a partir da junção dos álcalis do cimento e alguns tipos de minerais reativos que estão presentes nos agregados. Esse tipo de reação pode resultar em um gel expansivo, onde ao se dispor nos vazios do concreto e na superfície do agregado em contato com a pasta de cimento pode ocasionar fissuras generalizadas e assim comprometer a qualidade da estrutura (PAN et al., 2012). A deterioração no concreto devido as reações álcali-agregado pode causar a redução da vida útil da estrutura e afetar de forma significativa a sua durabilidade, já que expõe o concreto às condições ambientais e à ação de agentes agressivos, fato que acelera o processo de degradação. No Brasil, existe uma norma específica para a análise da reatividade álcaliagregado: ABNT NBR 15577 (2008). Esta norma está dividida em 6 partes:

Parte 1: Guia para avaliação da reatividade potencial e medidas preventivas para uso de agregados em concreto;

Parte 2: Coleta, preparação e periodicidade de ensaios de amostras de agregados para concreto;

Parte 3: Análise petrográfica para verificação da potencialidade reativa de agregados em presença de álcalis do concreto.

Parte 4: Determinação da expansão em barras de argamassa pelo método acelerado;

Parte 5: Determinação da mitigação da expansão em barras de argamassa pelo método acelerado;

Parte 6: Determinação da expansão em prismas de concreto.

As reações álcali-agregado podem ser de três tipos: reação álcali-sílica, reação álcali-silicato e reação álcali-carbonato, cada tipo dependente da composição mineralógica reativa do agregado. Diante aos problemas gerados por essas reações, diversos estudos têm procurado maneiras de minimizar estes efeitos. De acordo com Monteiro et al. (1997), a ação mais empregada para minimizar e até suprimir a 
reação álcali-agregado é substituir parcialmente o cimento por adições minerais, principalmente materiais pozolânicos.

Segundo Mehta (2008), em torno de 50 a 70\% da massa do clínquer presente no cimento Portland pode ser substituída por diversos materiais complementares. Estes materiais são rejeitos industriais e agroindustriais e podem ou não sofrer beneficiamento. Os materiais pozolânicos que são comumente utilizados para substituir parcialmente o cimento Portland, são a cinza volante, cinza de casca de arroz, escória de alto forno e sílica ativa. Com base no exposto, o presente trabalho tem como objetivo fazer um estado da arte sobre as principais adições minerais utilizadas para mitigar as reações álcali-agregado e verificar os seus efeitos.

\section{METODOLOGIA}

Foi realizada uma pesquisa sobre trabalhos que utilizaram adições minerais para diminuir ou suprimir as reações álcali-agregado em artigos nacionais, artigos internacionais, dissertações, teses e livros. A partir desta pesquisa elaborou-se um estado da arte, apresentando os principais resultados que os diversos autores obtiveram.

\section{DISCUSSÃO TEÓRICA}

\section{Patologias do Concreto}

Os fenômenos patológicos habitualmente apresentam manifestação externa característica, a partir da qual se pode ter uma ideia dedutiva quanto à natureza, à origem e aos mecanismos dos fenômenos envolvidos. Pode-se dizer que os problemas patológicos de maior gravidade nas estruturas em concreto armado, especialmente pelo seu evidente risco à integridade da estrutura, são a corrosão da armadura do concreto, as fissuras e as flechas excessivas das peças estruturais (HELENE, 1992).

De acordo com Helene (2005), dentre os processos que interferem na durabilidade do concreto armado, estão processos físicos e químicos, onde os mais relevantes dos processos químicos são a corrosão das armaduras, a penetração de cloretos, a carbonatação, o ataque por sulfatos e as reações álcali-agregado.

Segundo Poole (1992), as estruturas de concreto afetadas por reações álcali-agregado podem apresentar como manifestações patológicas fissuras, expansão ou desalinhamento dos elementos estruturais, exsudação de gel e lascamentos. Como é possível observar, o estudo relacionado a RAA com as patologias do concreto não são recentes. Porém, faz-se necessário continuar esse estudo, tendo em vista que os processos patológicos advindos da RAA tem grande ocorrência e merece um tratamento específico. 


\section{Reação Álcali-Agregado}

A deterioração do concreto causada pela reação álcali-agregado foi identificada pela primeira vez no ano de 1940, na Califórnia - EUA, por Stanton, quando se constatou inexplicáveis expansões em estruturas de diversos prédios escolares, pontes, pavimentos e construções portuárias. Ao investigar, Stanton chegou a conclusão que as expansões estavam relacionadas ao uso de cimento com alto teor de álcalis e que as deteriorações ocorridas foram devido à reação álcali-sílica (HOBBS, 1988).

A reação se manifesta no concreto por um padrão de fissuração, expansão e consequente deslocamento dos elementos estruturais, o que causa ainda a desagregação de fragmentos da superfície. Algumas vezes, ocorre a exsudação de gel sílico-alcalino resultante da reação, que se deposita na superfície do concreto (PAULON, 1981).

Segundo Bonato (2015), a reação álcali-agregado, é a reação química que ocorre no interior de uma estrutura de concreto, acontece entre os álcalis do cimento e os minerais dos agregados, sendo que geralmente os álcalis ou hidróxidos alcalinos também podem advir da água de amassamento, de aditivos químicos, de adições pozolânicas, entre outros.

A fissuração, é uma porta para agentes prejudiciais ao concreto como o $\mathrm{CO}_{2}$ que age no processo de corrosão das armaduras, ocorre devido à formação de gel que é parcialmente solúvel em água e pode expandir ou contrair com a perda ou ganho de água. Então, a variação de volume ocasiona uma pressão interna e, consequentemente, expansão e fissuração (SILVEIRA, 2007).

Segundo Paulon (1981), independentemente do tipo de reação álcali-agregado (álcali-sílica, álcalisilicato ou álcali-carbonato), a fissuração em forma de mapa pode ser observada em todos os casos, porém algumas características permitem diferenciar os três tipos. Conforme ilstrado na figura 1, há um bloco de fundação com problema de fissuração devido à reação álcali-agregado em Pernambuco.

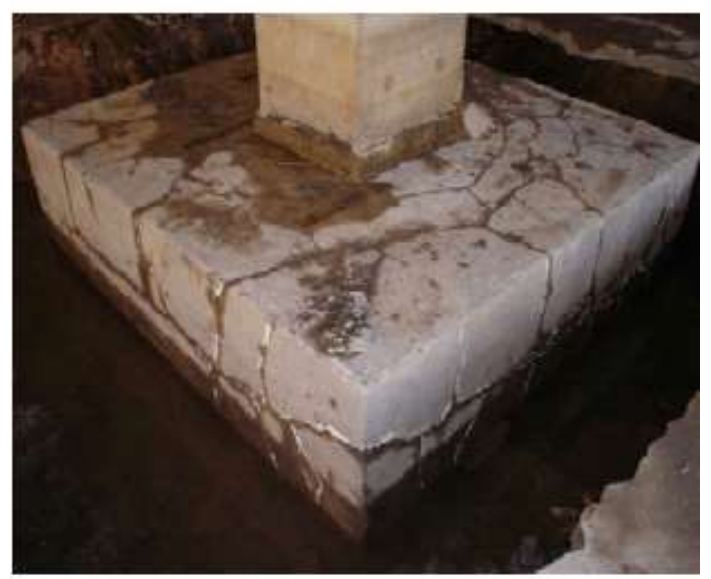

Figura 1: Fissuração de bloco de fundação afetado pela RAA. Fonte: Salles et al. (2003).

Vários fatores podem influenciar na intensidade da reação e no seu desenvolvimento no decorrer do tempo, como: a presença de agregado reativo no concreto e de álcalis na pasta de cimento, a presença de umidade e outras condições ambientais. A RAA é mais comum em obras que estejam expostas à umidade 
como barragens, pontes, viadutos, porém, podem ocorrer em edificações e obras habitacionais, em especial as fundações, onde o concreto fica em contato direto com áreas úmidas.

\section{Reação Álcali-Sílica}

As reações álcali-sílica acontecem quando a solução alcalina da pasta de cimento ou de uma fonte externa reagem com alguns minerais do grupo sílica (opala, calcedônia, cristobalita e tridimita) e com certos tipos de vidros naturais (vulcânicos) e artificiais (vidro pyrex) (SILVEIRA, 2007). Segundo Thalmann et al. (2001), a reação álcali-sílica é o tipo de reação mais conhecido e comum, é referida como a reação entre íons alcalinos $\left(\mathrm{OH}^{-}, \mathrm{Na}^{+}, \mathrm{K}^{+}\right)$, provenientes da solução dos poros do concreto, e a sílica $\left(\mathrm{SiO}_{2}\right)$, presente em alguns agregados.

De acordo com Glasser et al. (1981), o comportamento de algumas formas de sílica (sílica gel, quartzo, opala) em meio alcalino (hidróxido de sódio) ocorre, inicialmente, com uma reação ácido-base, quando os íons hidroxila $\left(\mathrm{OH}^{-1}\right.$ atacam as ligações do grupo silanol ( $\left.\mathrm{SiOH}\right)$, neutralizando-as. Posteriormente, ocorre a associação do cátion sódio $\left(\mathrm{Na}^{+}\right)$à estrutura, balanceando a carga negativa dos átomos de oxigênio e formando um gel sílico-alcalino. Por fim, ocorre o ataque do grupo siloxano pelos íons hidroxila $\left(\mathrm{OH}^{-1} \mathrm{em}\right.$ excesso levando à desintegração de sua estrutura e permitindo assim a adsorção de água e de íons alcalinos. A Figura 2 mostra exemplos de tipos de manifestações devido às reações álcali-sílica.

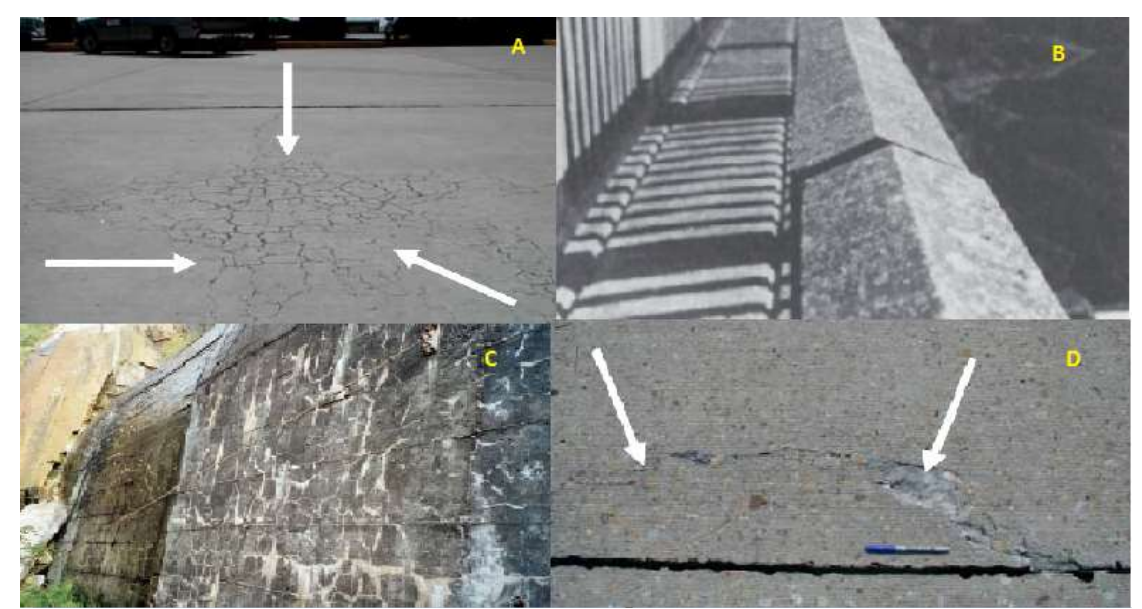

Figura 2: (A) Fissuras em forma de mapa em um pavimento de concreto; (B) Desalinhamento da crista do parâmetro de uma barragem; (C) Exsudação de gel; (D) pop-out.

Fontes: Poole (1992); Thalmann et al. (2001); Sarkar et al. (2009).

\section{Reação Álcali-Silicato}

A reação álcali-silicato ocorre entre os álcalis disponíveis no cimento e determinados tipos de silicatos presentes em rochas sedimentares (argilitos, siltitos e grauvacas), rochas metamórficas (ardósias, filitos, xistos, gnaisses, granulitos, quartzitos e hornfels) e ígneas (basalto). Ela é considerada uma reação mais lenta e complexa do que a reação álcali-sílica (KIHARA, 1993).

De acordo com Furnas (1997), os aspectos que tornam a rocha deformada vulnerável ao ataque de soluções alcalinas são a presença de quartzo intensamente deformado, devido ao deslocamento e 
imperfeições dos cristais; a presença de quartzo microcristalino, o qual possui maior superfície específica para reação; e a existência de cristais de silicatos deformados. Apesar da reação álcali-sílica ser considerada a mais frequente, no Brasil, a reação álcali-silicato é a mais encontrada. Isso se deve à maior parte das barragens atacadas por essa reação ter sido construída com agregados procedentes de quartzitos, granitos e gnaisses (VALDUGA, 2002).

\section{Reação Álcali-Carbonato}

Este tipo de reação ocorre entre os álcalis disponíveis no cimento e alguns agregados rochosos carbonáticos, como o calcário dolomítico argiloso (SILVEIRA, 2007). De acordo com Furnas (1997), a deterioração do concreto pela reação álcali-carbonato ocorre devido à desdolomitização do calcário e o consequente enfraquecimento da interface pasta-agregado. Nessa reação há a formação de brucita $\mathrm{Mg}(\mathrm{OH})_{2}$ e regeneração de hidróxidos alcalinos, não havendo formação de gel expansivo como na reação álcali-sílica.

\section{Efeito da adição de pozolanas na mitigação das reações álcali-agregado}

Segundo Mehta (2008), a utilização de adições minerais tem influência benéfica sobre a durabilidade do concreto, devido aos efeitos físicos associados com o tamanho das partículas, que são geralmente mais finas que as do cimento Portland, e pelas reações pozolânicas e cimentíceas. De acordo com a ASTM C 618/97 e a ABNT NBR 12653: 1992, pozolana é um material que, por si só, possui pouca ou nenhuma atividade cimentícea, porém, quando finamente dividida e na presença de água, reage com o hidróxido de cálcio à temperatura ambiente para formar compostos com propriedades cimentantes, reação na qual é chamada de reação pozolânica.

As pozolanas podem se originar tanto de materiais naturais como: tufos vulcânicos, terras diatomáceas, argilas calcinadas; assim como de subprodutos e resíduos industriais (cinza volante, sílica ativa e cinza de casca de arroz). Elas podem ser utilizadas como substituição de parte do cimento ou como adição em percentuais variáveis em relação à massa de cimento. A adição de materiais pozolânicos, além de combaterem a expansão causada pela reação álcali-agregado, melhora outras propriedades do concreto, como a permeabilidade, a resistência ao calor, a difusividade, e o tamanho da zona de transição, devido à presença de partículas sólidas menores.

Existem muitas proposições que buscam explicar o efeito da incorporação de adições minerais pozolânicas na reação álcali-agregado. A seguir serão apresentadas as diversas explicações de alguns autores sobre a utilização de pozolanas e seus efeitos nestas reações. Vivian (1983); Diamond (1997) e Hobbs (1988) constataram em seus estudos que a incorporação de materiais silicosos finamente moídos, ou pozolanas, poderiam agir de forma benéfica na redução das expansões nas reações álcali-agregado (teores ótimos). Porém, descobriram ainda que alguns teores podem agir de forma contrária, os chamados teores péssimos.

Segundo Ramachandran (1998), a eficácia com que as misturas de pozolanas naturais, cinza volante, cinza de casca de arroz, escória de alto forno e sílica ativa previnem os efeitos da reação álcali-agregado, vai 
depender da composição química das misturas, da quantidade adicionada, do tipo de agregado e do tipo de álcalis no cimento (Sódio, Potássio ou Lítio).

Para um determinado teor de álcalis do cimento, uma determinada quantidade de pozolana deve ser adicionada com o objetivo de produzir uma quantidade máxima de C-S-H e uma quantidade mínima de gel (SILVEIRA, 2007). Segundo Diamond (1997), as adições pozolânicas agem por meio de um mecanismo de reação de superfície, que reduz não só a concentração de álcalis, mas ainda a concentração de íons hidroxila $\left(\mathrm{OH}^{-}\right)$, isto é, o pH da solução da água dos poros.

Prezzi (1995) explicou que as adições minerais reduzem o pH da solução de água dos poros do concreto, tornando-a menos agressiva e diminuem a carga negativa da superfície da sílica. Quanto menor a concentração iônica na superfície carregada da partícula, menores a pressão e as expansões que são desenvolvidas.

Chatterji et al. (1989) apontaram como responsável da redução da expansão, o consumo de $\mathrm{Ca}(\mathrm{OH})_{2}$ formado durante a hidratação do cimento, sendo a adição de minerais importantes contribuidores para este fato. De acordo com Wang et al. (1991), o Ca(OH) 2 possui duas funções no mecanismo da reação álcali-sílica. Age mantendo o pH alto da solução da água dos poros, isto é, uma alta concentração de $\mathrm{OH}^{-}$e age como fonte de $\mathrm{Ca}^{2+}$, cuja liberação pode produzir gel silico-alcalino expansivo.

Bhatty (1985) concluiu que as pozolanas reduzem a expansão causada pela reação durante a produção de C-S-H e silicatos hidratados com baixa relação Cálcio/Sílica (Ca/Si). Estes hidratos podem reter o álcali adicional, reduzindo assim a quantidade de álcalis disponível para a reação com os agregados reativos, eliminando o efeito nocivo da expansão. Os resultados da sua pesquisa indicaram que a quantidade de álcalis retida aumentou com o aumento da adição de pozolanas.

A partir dessas considerações, foi possível observar que a adição de pozolana auxilia na redução da expansão do concreto, inibindo desta forma as reações álcali-agregado. A seguir, serão mostrados os principais tipos de adições pozolânicas utilizadas por alguns pesquisadores e seus respectivos efeitos na mitigação das reações álcali-agregado.

Duchesne et al. (1994) foram responsáveis por analisar o efeito de algumas adições minerais como sílica ativa, cinza volante e escória de alto forno, com o objetivo de reduzir a expansão devido às reações álcali-agregado. A contribuição das pozolanas foi avaliada por dois parâmetros: consumo de $\mathrm{Ca}(\mathrm{OH})_{2}$ e análise da solução de água dos poros. Os autores chegaram a conclusão que quanto maior o conteúdo de material suplementar (cimento substituído por pozolana), maior o consumo de $\mathrm{Ca}(\mathrm{OH})_{2}$. Não foi constatada nenhuma correlação entre o teor de $\mathrm{Ca}(\mathrm{OH})_{2}$ e a redução da expansão do concreto. Desta forma, o consumo $\mathrm{Ca}(\mathrm{OH})_{2}$, observado nas análises parece ser apenas uma consequência da reação pozolânica, em função da redução da alcalinidade na solução de água dos poros.

Nas análises de Munhoz (2007), foi verificado que com o aumento do teor de adições de escória de alto-forno, cinza volante, metacaulim e de silica ativa, a expansão devido a reação álcali-agregado é reduzida. Silveira (2007) observou o mesmo, porém analisando os efeitos da adição de cinzas de casca de arroz. 
Silveira (2007) buscou em seu trabalho investigar a influência da substituição parcial do cimento Portland por cinza de casca de arroz em concretos sujeitos à reação álcali-agregado. 0 trabalho consistiu na realização de ensaios de expansão acelerada em barras de argamassa (ASTM C1260/94) moldadas com cimento Portland tipo CP - I S 32, com teores de 12,5; 25 e 50\% de dois tipos de cinza de casca de arroz, em substituição parcial ao cimento, e quatro diferentes tipos de agregados (basalto B, basalto BGO, granito e riodacito). Ele concluiu que o efeito da incorporação de cinza de casca de arroz na redução da expansão devido a RAA está relacionada ao tipo de cinza, ao tipo de agregado e ao teor de cinza utilizado. Ele verificou que a melhor combinação agregado-cinza de casca de arroz, onde se obteve menor expansão foi com 50\% de cinza de casca de arroz (tipo E) e agregado riodacito. A pior combinação, onde obteve-se a maior expansão, foi com $25 \%$ de cinza de casca de arroz (tipo B) e basalto BGO.

Silva et al. (2007) estudaram a influência da utilização da cinza de casca de arroz (CCA) em substituição parcial ao cimento nas expansões devido às reações álcali-agregado. Foram analisados diferentes teores de CCA, sendo $0 \%$ o traço referência e $5 \%, 10 \%$ e $25 \%$ substituindo o cimento. Os resultados obtidos no ensaio de redução da expansão conforme a ABNT NBR 12651: 1992 mostrou que a CCA reduz consideravelmente a expansão de argamassas devido à reação com os álcalis do cimento $(94,29 \%)$, quando o limite mínimo de redução exigido pela norma para uma pozolana é de $75 \%$. Embora no ensaio de reação álcali-agregado ASTM C-1260: 1994 os valores de expansão tenham ficado acima do limite permitido para considerar o material inócuo, tanto o teor de $5 \%$ quanto o de 10\% de CCA obtiveram resultados melhores (expandiram menos) que o traço referência, como se pode observar na figura 3.

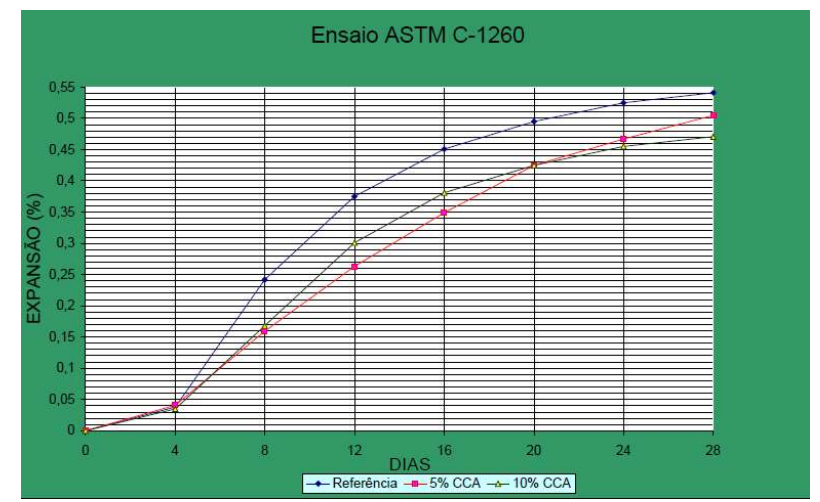

Figura 3: Gráfico do ensaio de reação álcali-agregado. Fonte: (SILVA et al., 2007).

Rangaraju et al. (2009) estudaram a influência da substituição parcial do cimento por cinza volante (com teores baixos, intermediários e altos de cal em sua composição) e escória granulada de alto forno na mitigação das reações álcali-sílica. As cinzas foram investigadas em níveis de substitituição de cimento de 15, 25 e 35\% em massa. Já a escória foi investigada nos teores de 40 e $50 \%$ em substituição ao cimento. Os autores concluiram em seus resultados que as cinzas volantes com teores de cal baixos e intermediários, nas proporções de substituição de 25 e 35\% tiveram um efeito significativo na suspensão das expansões. Já as cinzas volantes com alta concentração de cal foram ineficazes na mitigação, sendo que agravaram as expansões em vez de suprimir, considerando todos os níveis de substituição. A proporção de $15 \%$ em substituição ao cimento foi inadequada para mitigar a expansão das barras de argamassa com as três cinzas 
volantes (baixa, intermediária e alta concentração de cal). Em relação a utilização da escória em substituição ao cimento, os autores observaram que a substituição de $40 \%$ não foi eficaz para a mitigação, porém, o uso de escória nas barras de argamassa a 50\% em substituição ao cimento foi adequado para mitigar a expação aos 14 dias.

Moser et al. (2010), estudaram o potencial de misturas binárias (cimento e metacaulim ou cinza volante) e ternárias (cimento, metacaulim e cinza volante) para mitigar as reações álcali-sílica, sendo analisados metacaulim com duas distribuições de tamanho de partícula diferentes e cinzas volantes classe C. Os dois tipos de metacaulim foram, o "Mka" e "Mkb", com áreas superficiais de 11,2 e 25,4 m²/g, respectivamente. $O$ estudo foi composto pela análise de doze misturas de argamassas, sendo uma referência, misturas binárias de $8 \%$ e $15 \%$ de metacaulim e 25\% de cinza volante classe C e misturas ternárias de 3\%, 5\% e $8 \%$ de metacaulim com $25 \%$ de cinza volante classe C.

Os resultados mostraram que as misturas binárias de metacaulim ou cinza volante classe $\mathrm{C}$ reduziram a expansão devido as reação álcali-sílica, em 55-90\% e 25-37\% em relação à mistura referência, respectivamente. Ao incorporar metacaulim com um tamanho de partícula médio mais baixo, as misturas binárias mostraram uma maior redução na expansão em comparação com as cinzas volantes Classe C. As misturas ternárias do metacaulim e as cinzas volantes Classe $C$ resultaram em uma expansão marginalmente maior do que as misturas binárias que incorporam a mesma quantidade de metacaulim.

Lucca (2010) analisou o teor de substituição de cimento Portland por cinza volante, que se mostrou eficiente na redução dos efeitos deletérios da reação álcali-agregado em concretos fabricados na região de Porto Alegre-RS. Em seu estudo, foram realizados ensaios de expansão de barras de argamassa pelo método acelerado, moldadas com cimento Portland tipo CP V - ARI, brita basáltica e diferentes teores de cinzas volantes de finuras distintas em substituição parcial ao cimento, para verificação da mitigação da expansão de acordo com a ABNT NBR 15577-5: 2008. A correlação entre os teores de substituição de cimento Portland por cinza volante e a redução da reação expansiva foi analisada e notou-se a eficiência da adição em combater esse tipo de reação, onde em teores de $15 \%$ já foi possível reduzir os efeitos da expansão para limites recomendados pela ABNT NBR 15577-1: 2008.

Höehr (2015) avaliou em seu trabalho o potencial reativo frente à reação álcali-sílica, da sílica ativa e de dois tipos de cinzas de casca de arroz, uma comercial e outra residual. Adotou-se teores de 5 a $50 \%$ como substituição parcial ao cimento Portland padrão. Um dos ensaios que o autor utilizou foi o método acelerado em barras de argamassa, segundo a ABNT NBR 15577-4: 2008. Os resultados obtidos apontaram que ambas as cinzas de casca de arroz foram reativas frente às reações álcali-sílica. Porém, com o teor de 50\%, ambas se mostraram inócua à reação. Já a sílica ativa foi considerada inócua em todos os teores avaliados.

Medeiros et al. (2016) estudaram a influência da substituição parcial (15\%) do CP V - ARI por fíler calcário e resíduo de cerâmica vermelha - RCV (com diferentes tempos de moagem) na mitigação da expansão das argamassas devido às reações álcali-sílica ao longo de 66 dias. A figura 4 mostra os resultados obtidos de acordo com o estudo em questão. 


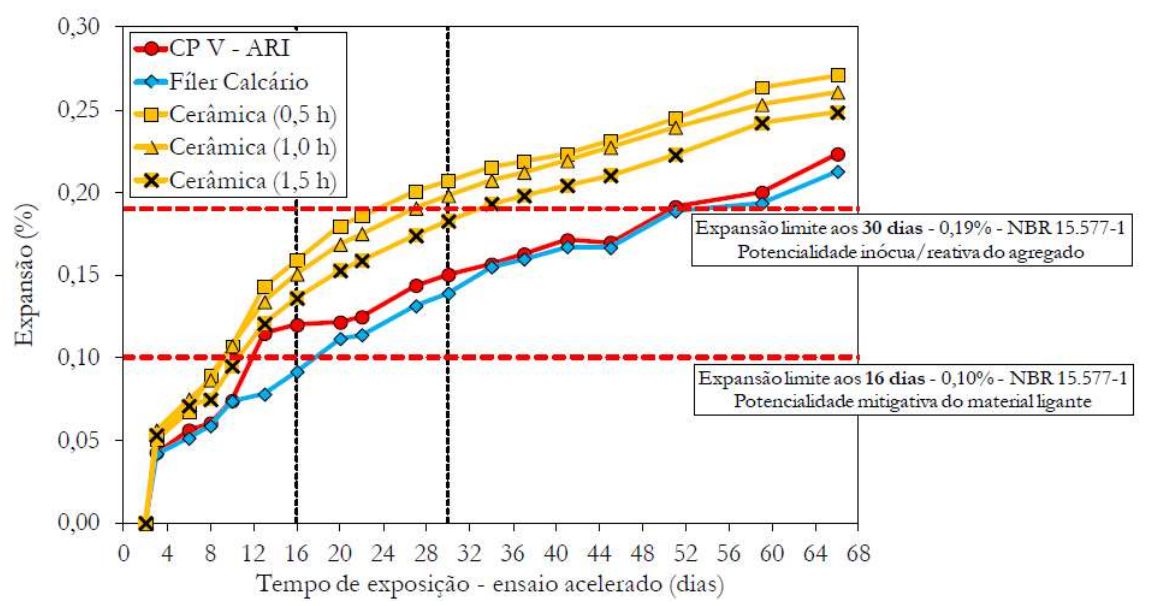

Figura 4: Reação álcali-sílica: evolução da expansão média das barras de argamassa com 100\% de cimento comparado com substituição de $10 \%$ do cimento por adições minerais. Fonte: Medeiros et al. (2016).

De acordo com os resultados da figura 4, Medeiros et al. (2016) concluiram que o cimento CPV - ARI, utilizado como padrão, resultou em um sistema com expansão superior ao limite recomendado pela ABNT NBR 15.577 - 1. A utilização do fíler calcário na composição das argamassas aparentemente atribuiu potencial de mitigação a esta adição, embora, estatisticamente, o resultado possa ser considerado idêntico ao valor limite de $0,10 \%$. Os efeitos físicos do fíler calcário interferem na microestrutura da matriz hidratada, o que propiciou redução da expansão da argamassa. O RCV, independentemente da finura, além de não mitigar a reação álcali-sílica, propiciou a expansão da argamassa a valores superiores ao observado na referência. O maior tempo de moagem do resíduo de cerâmica vermelha tendeu a reduzir a expansão da argamassa. A análise geral, ao longo de 66 dias, mostra que o comportamento expansivo da argamassa com fíler calcário tende a se equiparar à série de referência após 20 dias, mantendo esta tendência ao longo do período estudado. Já a série contendo RCV, nas diferentes finuras, tende a manter maior expansão em comparação à série de referência para as idades avaliadas.

De fato, a maior expansão ocorre sempre na amostra de resíduo de cerâmica vermelha com menor tempo de moagem. Cabe salientar que a utilização de RCV, nos tempos de moagem de 0,5 e 1,0 hora, atribuiu potencialidade reativa às respectivas argamassas, pois estas superaram o valor limite de expansão de $0,19 \%$ aos 30 dias. A argamassa contendo o resíduo moído por 1,5 horas apresentou expansão próxima ao limite normativo para a referida idade, o que atribui a esta adição mineral incerteza sobre a sua adequabilidade para a mitigação da reação álcali-sílica. Resumindo, o resíduo de cerâmica vermelha potencializa a expansão da argamassa quando da presença de álcalis na solução aquosa dos poros da matriz hidratada.

Souza et al. (2016) estudaram o emprego da escória de aciaria elétrica na minimização da expansão decorrente da reação álcali-agregado, baseado nos métodos de ensaio estabelecidos pela ABNT NBR 15577: 2008, ou seja, como substituição parcial do cimento. Observou-se que aos 16 dias ocorreu redução significativa da expansão das barras moldadas com $10 \%$ e $20 \%$ de escória de aciaria, obtendo redução de quase $54 \%$. Porém, a redução não levou a expansão inferior ao preconizado por norma, de $0,10 \%$. Alguns fatos da sua análise o levaram a concluir que uma escória com alto teor de óxido de cálcio ( $\mathrm{CaO})$ pode ter 
efeito inverso ao esperado, podendo mitigar a reação álcali-agregado, mas mesmo assim expandir pela existência de óxido de cálcio livre e óxido de magnésio.

\section{CONCLUSÕES}

Conforme a análise dos resultados obtidos por vários pesquisadores, foi possível constatar que a técnica da utilização de materiais pozolânicos como substituição parcial do cimento Portland para mitigar reação álcali-agregado é bastante explorada, desde pesquisas mais antigas até as recentes. Observou-se a utilização de pozolanas diversificadas para esta mitigação, como: cinza de casca de arroz, cinza volante, escória granulada de alto forno, escória de aciaria, sílica ativa, metacaulim, fíler calcário e resíduo de cerâmica vermelha.

Alguns resultados possibilitaram concluir que estas adições ajudam a reduzir as expansões nas reações álcali-agregado, porém, se não tiver um teor ótimo, podem agir de forma contrária, facilitando as reações. Portanto, apesar de ser uma técnica bastante estudada, necessita-se de pesquisas com maior complexidade para que se possa caracterizar os efeitos deléterios e determinar os teores de adições pozolânicas que contribuem para a difusão das reações álcali-agregado (teores péssimos).

\section{REFERÊNCIAS}

ABNT. Associação Brasileira de Normas Técnicas. Agregados: Reatividade álcali-agregado. Rio de Janeiro: ABNT, 2008.

ABNT. Associação Brasileira de Normas Técnicas. Agregados: Reatividade álcali-agregado - Parte 4: Determinação da expansão em barras de argamassa pelo método acelerado. Rio de Janeiro: ABNT, 2008.

ABNT. Associação Brasileira de Normas Técnicas. Materiais Pozolânicos: Especificação. Rio de Janeiro: ABNT, 1992.

ASTM. Anual Book of Astm Standards. American society for testing and materials. Philadelfia: 1997.

BHATTY, M. S. Y.. Mechanism of pozzolanic reactions and control of alkali-aggregate expansion. Cement, Concrete and Aggregates, West Conshohocken, v.7, n.2, 1985.

BONATO, L. C.. Reação álcali-agregado: principais causas e estudo de reatividade potencial. Campo Mourão, 2015.

CHATTERJI, S.; THAULOW, N.. Studies on alkali-silica reaction. Cement and Concrete Research, West Conshohocken, 1989.

DAVIES G.; OBERHOLSTER R. E.. Use of the NBRI accelerated test to evaluate the effectiveness of mineral admixtures in preventing the alkali-silica reaction. Cement and Concrete Research, West Conshohocken, v.17, n.1, 1987.

DIAMOND, S.. Alkali Silica Reactions: Some Paradoxes. Cement and Concrete Composites, Amsterdã, v.19, 1997.

DUCHESNE, J.; BÉRUBÉ, M. A.. The effectiveness of suplementary cementing materials in supressing expansion due to ASR: another look at the reaction mechanism: pore solution chemistry. Cement and Concrete Research, West Conshohocken, v.24, n.2, 1994.

DUCHESNE, J.; BÉRUBÉ, M.A.. The effectiveness of suplementary cementing materials in supressing expansion due to ASR: another look at the reaction mechanism: concrete expansion and portlandite depletion. Cement and Concrete Research, West Conshohocken v.24, n.1, 1994.

FUSCO, P.B.. Estruturas de Concreto. São Paulo: McGraw-Hill do Brasil, v.1, 1976.

GLASSER, L. S. D.; KATAOKA, N.. The chemistry of alkali-aggregate reaction. Cement and Concrete Research, West Conshohocken, v.11, 1981.

HASPARYK, N. P.. Investigação de concretos afetados pela reação álcali-agregado e caracterização avançada do gel exsudado. Tese (Doutorado em 
Engenharia) - Universidade Federal do Rio Grande do Sul, Porto Alegre, 2005.

HELENE, P.. Manual de Reparo, Proteção e Reforço de Estruturas de Concreto. São Paulo: Editora Rehabilitar, 2005.

HELENE, P.. Manutenção para Reparo, Reforço e Proteção de Estruturas de Concreto. 2 ed. São Paulo: Pini, 1992.

HOBBS, D. W.. Alkali-silica reaction in concrete. London: 1988.

HÖEHR, G. T.. Influência da incorporação de cinza da casca do arroz e de sílica ativa no cimento Portland frente à reação álcali-sílica. Tese (Doutorado em Engenharia) - Universidade Federal do Rio Grande do Sul, Porto Alegre, 2015.

ISAIA, G. C.. Efeito de misturas binárias e ternárias de pozolanas em concreto de elevado desempenho: um estudo da durabilidade com vistas à corrosão da armadura. Tese (Doutorado) - Escola Politécnica da Universidade de São Paulo, São Paulo, 1995.

KIHARA, Y.. Reação álcali-agregado: mecanismo, diagnose e casos brasileiros. In: CONGRESSO BRASILEIRO DE CIMENTO, 3. Anais. São Paulo, ABCP, 1993.

LANE, D.S.; OZYILDIRIM, C.. Preventive measures for alkali-silica reactions (binary and ternary systems). Cement and Concrete Research, West Conshohocken, p.1281-1288, 1999.

LAPA, J. S.. Patologia, recuperação e reparo das estruturas de concreto. Monografia (Especialização em Engenharia Civil) - Universidade Federal de Minas Gerais, Belo Horizonte, 2008.

LUCCA, A. C. K.. Reação Álcali-Agregado: Efeito do uso de cinza volante. Porto Alegre, 2010.

MEDEIROS, M. H. F.; SOUZA, D. J.; FILHO, J. H.; ADORNO, C. S.; QUARCIONI, V. A.; PEREIRA, E.. Resíduo de cerâmica vermelha e fíler calcário em compósito de cimento Portland: efeito no ataque por sulfatos e na reação álcali-sílica. Revista Matéria, Rio de Janeiro, v.21, n.2, 2016.

MEHTA, P. K.. Concreto Sustentável. Revista Téchne. São Paulo: 2008.

MOESER, R. D.; JAYAPALAN, A. R.; GARAS, V. Y.; KURTIS, K. E.. Assessment of binary and ternary blends of metakaolin and class C fly ash for alkali-silica reaction mitigation in concrete. Cement and Concrete Reserach, West Conshohocken, 2010.
MONTEIRO, P. J. M.; WANG, K.; SPOSITO, G.; SANTOS, M. C.; ANDRADE, W. P.. Influence of mineral admixtures on the alkali aggregate reaction. Cement and Concrete Research, West Conshohocken, v.27, n.12, 1997.

MUNHOZ, F. A. C.. Effect of mineral admixtures in controlling the alkali-silica reaction and alkali-silicate reaction. São Paulo, 2007.

PAN, J. W.; FENG, Y. T.; WANG, J. T.; SUN, Q. C.; ZHANG, C. H.; OWEN, D. R. J.. Modeling of alkali-silica reaction in concrete: a review. Frontiers of Structural and Civil Engineering, v.6, n.1, 2012.

PAULON, V. A.. Reações Álcali-Agregado em Concreto. Dissertação (Mestrado) - Escola Politécnica da Universidade de São Paulo, 1981.

POGGIALI, F. S. J.. Durabilidade de estruturas de concreto em usinas siderúrgicas. Monografia (Especialização em Engenharia Civil) - Universidade Federal de Minas Gerais, 2009.

POOLE, A. B.. Introduction to alkali-aggregate reaction in concrete. In: The alkali-silica reaction in concrete. Glasgow: Blackie and Son, 1992.

PREZZI, M.. Analysis of the Mechanism of Concrete Deterioration. Berkeley: University of California, 1995.

RAMACHANDRAN, V. S.. Alkali-aggregate expansion inhibiting admixtures. Cement and Concrete Composites, Amsterdã, v.20, n.3, 1998.

RANGARAJU, P. E. P. R.; DESAI, J.. Effectiveness of fly ash and slag in mitigating alkali-silica reaction induced by deicing chemicals. Journal of Materials in Civil Engineering, 2009.

SALLES, F. M.; SANTO, T. D. E; MARQUES, M. L.. A reação álcali-agregado em concreto: efeito, diagnóstico e prevenção. In: WORKSHOP CONCRETO: Durabilidade, Qualidade e Novas Tecnologias, 2. Anais. Ilha Solteira: Sato, 2003.

SARKAR, L.; ZOLLINGER, D. G.; MUKHOPADHYAY, K.; SEUNGWOOK, L.; SHON, C.. Handbook for identification of alkali-silica reactivity in airfield pavement. Federal Aviation Administration, n.150, 2009.

SILVA, E. J.; TASHIMA, M. M.; AKASAKI, J. L.. Estudo de reações expansivas em argamassas de cimento Portland com cinza de casca de arroz (CCA). HOLOS Environment, v.7, n.1, 2007.

SILVEIRA, A. A.. Contribuição ao estudo do efeito da incorporação de cinza de casca de arroz em concretos 
submetidos à reação álcali-agregado. Tese

(Doutorado) - Universidade Federal do Rio Grande do Sul, Porto Alegre, 2007.

SOROUSHIAN, P.; ALHOZAIMY, A.. Effects of class F flyash on alkali-silica reaction. In: Durability of Bulding Materials and Components. Lexington: 1993.

SOUZA, L.; ZOLETT, E. R.; CARRAZEDO, R.. Estudo dos efeitos do uso da escória de aciaria na expansão de corpos de provas sujeitos à reação álcali-agregado. Revista IBRACON de Estruturas e Materiais, v.9, n.4, 2016.

TAYLOR, H. F. W.. Cement Chemistry. 2 ed. London: 1997.

THALMANN, C.; ZINGG, J.; RYTZ, G.; STRAHM, K.; WYSS, C.. Verhinderung Von Betonschäden infolge Alkali-Aggregat-Reaktion. Zürich, 2001.
VALDUGA, L.. Reação álcali-agregado: mapeamento de agregados reativos do estado de São Paulo. Dissertação (Mestrado em Engenharia Civil) Universidade Estadual de Campinas, Campinas, 2002.

VIVIAN, H. E.. The process of alkali-aggregate reaction. Proceedings. Alkali in Cement and Concrete. London: 1983.

WANG, H.; GILLOTT, J. E.. Mechanism of alkali-silica reaction and the significance of calcium hydroxide. Cement and Concrete Research, West Conshohocken, v.21, 1991.

XUEQUAN, W.; HONG, Z.; XINKAI, H.; HUSEN, L.. Study on steel slag and fly ash composite Portland cement. Cement and Concrete Research, West Conshohocken, v.29, 1999. 